\title{
Overvoltage and Insulation Coordination of Overhead Lines in Multiple-Terminal MMC-HVDC Link for Wind Power Delivery
}

\author{
Huiwen He, Lei Wang, Peihong Zhou, and Fei Yan \\ State Key Laboratory of Power Grid Environmental Protection, China Electric Power Research Institute, Wuhan 430074, China \\ Correspondence should be addressed to Huiwen He; husthhw@126.com
}

Received 2 June 2017; Revised 16 August 2017; Accepted 30 August 2017; Published 25 October 2017

Academic Editor: Tao Wang

Copyright (C) 2017 Huiwen He et al. This is an open access article distributed under the Creative Commons Attribution License, which permits unrestricted use, distribution, and reproduction in any medium, provided the original work is properly cited.

\begin{abstract}
The voltage-sourced converter-based HVDC link, including the modular multilevel converter (MMC) configuration, is suitable for wind power, photovoltaic energy, and other kinds of new energy delivery and grid-connection. Current studies are focused on the MMC principles and controls and few studies have been done on the overvoltage of transmission line for the MMC-HVDC link. The main reason is that environmental factors have little effect on DC cables and the single-phase/pole fault rate is low. But if the cables were replaced by the overhead lines, although the construction cost of the project would be greatly reduced, the single-pole ground fault rate would be much higher. This paper analyzed the main overvoltage types in multiple-terminal MMC-HVDC network which transmit electric power by overhead lines. Based on $\pm 500 \mathrm{kV}$ multiple-terminal MMC-HVDC for wind power delivery project, the transient simulation model was built and the overvoltage types mentioned above were studied. The results showed that the most serious overvoltage was on the healthy adjacent line of the faulty line caused by the fault clearing of DC breaker. Then the insulation coordination for overhead lines was conducted according to the overvoltage level. The recommended clearance values were given.
\end{abstract}

\section{Introduction}

The voltage-sourced converter- (VSC-) based high-voltage DC (HVDC) transmission system is considered for a wide range of applications for wind power, photovoltaic energy, or other kinds of new energy delivery and grid-connection due to flexibly control of active power and reactive power output capability [1-4]. The Nanhui MMC-HVDC demonstration project and the Nanao multiple-terminal MMC-HVDC link have been put into operation already and achieved the stable and reliable wind power transmission $[5,6]$.

At present, the study focuses on the MMC principles and controls and less research has been done on the overvoltage of transmission line for the MMC-HVDC project. And there are few studies on the overvoltage characteristics of multiterminal MMC-HVDC $[7,8]$. State Grid Beijing Economic and Technical Research Institute has done research on the Dalian MMC-HVDC project considering the short circuit fault at AC bus, grid side and valve side of connection transformer, smoothing reactor, and DC pole bus. According to the simulation results of overvoltage, the reference voltage and switching impulse withstanding voltage of MOAs in the converter station were determined [9]. Based on the Trans Bay MMC-HVDC project, Zhejiang University studied the 14 kinds of fault and found the most serious overvoltages were caused by the single-phase grounding fault at valve side of converter transformer, the short circuit of transformer, the ground short circuit fault at valve head, DC bus grounding fault, and DC line grounding fault. The MOA configuration and insulation coordination scheme were proposed. The withstanding voltages of equipment were determined by deterministic method and the margin coefficient between withstand voltage and impulse overvoltage could be selected as $15 \%, 20 \%$, and $25 \%$ for switching impulse, lighting impulse, and steep impulse, respectively [10].

The researches mentioned above were focused on the converter station. Most of the MMC-HVDC projects adopt cables for power transmission all around the world. The cables buried in the ground are not affected by the surrounding environment, so the failure rate is lower $[11,12]$. However, cables lines are expensive and the overhead lines can greatly reduce the cost of construction. The overhead lines are susceptible to the surrounding environment, such as lightning and pollution, and the single-pole grounding fault rate is 
much higher than using cable lines. Therefore, it is necessary to study the overvoltage generated by overhead line faults to support the design of line insulation.

This paper focuses on the overvoltage level of overhead lines in multiple-terminal MMC-HVDC project. Firstly it pointed out the main overvoltage types of overhead lines in multiple-terminal MMC-HVDC link. Based on an $\pm 500 \mathrm{kV}$ multiple-terminal MMC-HVDC for wind power delivery project, the transient simulation model was built and various overvoltage types mentioned above were studied. Then the insulation coordination for overhead lines was conducted according to the overvoltage level. In the end the recommended clearance values were given.

This paper is organized as follows. Section 2 is devoted to analyzing the main overvoltage types of overhead lines in multiple-terminal MMC-HVDC link and the differences between it and conventional point-to-point LCC-HVDC project while Section 3 presents the simulation overvoltage results based on a multiple-terminal MMC-HVDC project according to Section 2. Then insulation coordination for overhead lines is conducted and the recommended clearances are given in Section 4. Finally, conclusions are drawn in Section 5 .

\section{Overvoltage Types of Overhead Line in Multiple-Terminal MMC-HVDC Project}

LCC-HVDC systems are usually 2 terminals adopting overhead transmission lines and the occurrence probability of single-pole grounding fault is the highest. Statistical data show that the single-pole lightning flashover rate of $\pm 500 \mathrm{kV}$ DC transmission lines is 0.28 times per $100 \mathrm{~km}$ every year. In a bipolar operation, a grounding fault occurring at one pole will induce the slow front overvoltage at the sound pole through the coupling between two poles and reflection and refraction of traveling wave at both ends of line. The magnitude of the overvoltage can be estimated by the following formula:

$$
U_{p}=U_{d c}\left(1+\frac{Z_{m 0}-Z_{m 1}}{Z_{m 0}+Z_{m 1}+2 R_{e}}\right),
$$

where $Z_{m 0}$ and $Z_{m 1}$ are zero sequence and positive sequence wave impedance of transmission line, respectively; $R_{e}$ is the grounding resistance.

The induced overvoltage at sound pole caused by singlepole grounding fault should also be considered for overhead lines in multiple-terminal MMC-HVDC project and the magnitude of the overvoltage can be estimated by formula (1) too. In order to improve the availability of MMC-HVDC project, the DC circuit breaker would be installed for fault clearing at DC side. So the line fault clearing overvoltage and reclosing overvoltage should be considered.

(1) The line fault clearing overvoltage mainly refers to the overvoltage on the sound pole line and the adjacent sound line generated by the fault tripping. It is equivalent to superimposing a current source with a reverse fault current on the circuit breaker when the circuit breaker interrupts the fault current. The current wave propagation and reflection on the adjacent sound line form transient overvoltage. The fault current is related to the main circuit parameters of converter station, the operation characteristics of DC circuit breaker, and the fault grounding resistance.

(2) When the DC line is switched on or reclosing, the overvoltage is generated due to the difference between the initial voltage of the line to the ground and the forced voltage at the end of the transition process. The magnitude of the overvoltage can be estimated by the following formula:

$$
U_{p c}=2 U_{w}-U_{0},
$$

where $U_{w}$ is the forced voltage at the end of the transition process and $U_{0}$ is the initial voltage of the line to the ground.

Therefore 3 kinds of overvoltage are as follows, which should be studied for overhead lines of multiterminal MMCHVDC systems:

(1) Induced overvoltage on healthy pole line caused by single-pole grounding fault

(2) Fault clearing overvoltage

(3) Closing and reclosing overvoltage.

\section{Analysis of Overvoltage of Overhead Transmission Lines in Multiple-Terminal MMC-HVDC Project}

\subsection{Simulation Parameters}

3.1.1. Main Circuit Parameter. A 4-terminal $\pm 500 \mathrm{kV}$ MMCHVDC for wind power delivery project, using half bridge and real bipolar connection, has 245 levels and DC rated voltage is $535 \mathrm{kV}$. The rated voltage of AC power network is $230 \mathrm{kV}$ at delivery end $\mathrm{A}$, which can send wind power out with $17 \mathrm{kA}$ three-phase short circuit current, and the rated capacity of A is $3000 \mathrm{MW}$ under the normal operation in island. The rated voltage of AC power network is $230 \mathrm{kV}$ at delivery end $\mathrm{B}$, which can send wind power out with $17 \mathrm{kA}$ three-phase short circuit current, and the rated capacity of B is $1500 \mathrm{MW}$ under the normal operation in island. The rated voltage of AC power network is $525 \mathrm{kV}$ at delivery end $\mathrm{C}$, which can send wind power out with $18 \mathrm{kA}$ three-phase short circuit current, and the rated capacity of $\mathrm{C}$ is $1500 \mathrm{MW}$. The rated voltage of AC power network is $525 \mathrm{kV}$ at delivery end $\mathrm{D}$, which can send wind power out with $63 \mathrm{kA}$ three-phase short circuit current, and the rated capacity of D is $3000 \mathrm{MW}$.

The lengths of DC transmission lines of 4-terminal system are shown in Figure 1. The type of conductors is 4 $\times \mathrm{JL} / \mathrm{G} 2 \mathrm{~A}-720 / 50$ with $12.8 \mathrm{~m}$ pole distance, and the type of ground wire is OPGW-150 with $12 \mathrm{~m}$ horizontal distance, together with the model JNRLH60/G1A-400/35 of metallic return line which has the horizontal distance of $9 \mathrm{~m}$. Typical tower model of tangent tower is shown in Figure 2, and the transmission line is simulated by Frequency Dependent (Phase) Model in PSCAD. In the converter station, the 


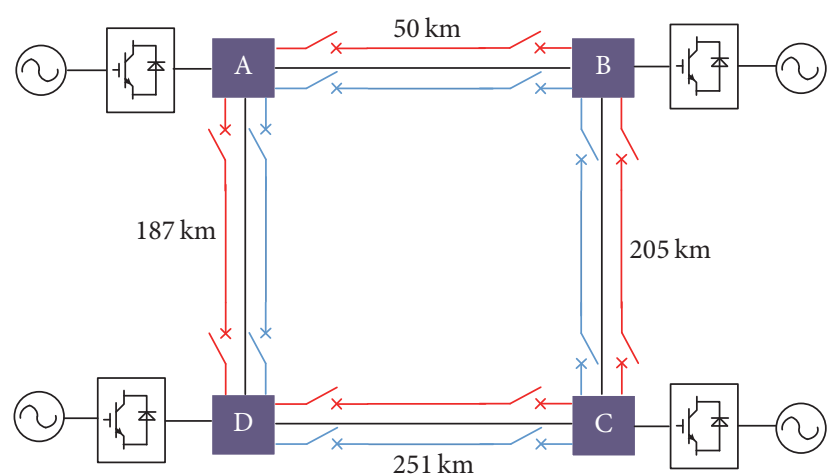

FIgURE 1: Schematic diagram of 4-terminal transmission lines.

current limiting reactors are arranged on the pole lines and the metallic return lines; the values of reactance are $150 \mathrm{mH}$ on the pole line and $300 \mathrm{mH}$ on the neutral line. The reference voltage of pole line arrester is $629 \mathrm{kV}$ and residual voltage is $904 \mathrm{kV}$ under switch operation with $2 \mathrm{kA}$ current.

According to empirical equation (3), the arc resistance $R_{G}$ in the air can be calculated:

$$
R_{G} \approx 1050 \frac{L_{G}}{I_{G}},
$$

where $L_{G}$ is the length of arc and $I_{G}$ is the rms. of current with the unit ampere. In the simulation, the sum resistance of arc and grounding tower is $4 \Omega$.

3.1.2. Control and Protection Model of Converter Station. A double closed-loop controller is established in PSCAD to achieve converter station-level control. Double closed-loop control can be divided into an outer loop controller and an inner loop controller. The outer loop controller can calculate the current reference value of the current-mode inner loop controller according to the active and the reactive power command. The inner loop controller keeps the $d q$ axis current tracking its reference value by adjusting the output voltage of the inverter. The control system used in the simulation is shown in Figure 3 [13-16].

According to Figure 3, the dynamic differential equation of AC side in three-phase stationary coordinate system is shown as

$$
\left[\begin{array}{l}
u_{s a} \\
u_{s b} \\
u_{s c}
\end{array}\right]=L \frac{d}{d t}\left[\begin{array}{l}
i_{s a} \\
i_{s b} \\
i_{s c}
\end{array}\right]+R\left[\begin{array}{l}
i_{s a} \\
i_{s b} \\
i_{s c}
\end{array}\right]+\left[\begin{array}{l}
u_{c a} \\
u_{c b} \\
u_{c c}
\end{array}\right],
$$

where $u_{s a}, u_{s b}$, and $u_{s c}$ are the measured phase A, phase $\mathrm{B}$, and phase $C$ voltages at grid side of converter transformer, respectively. $i_{s a}, i_{s b}$, and $i_{s c}$ are the measured phase $\mathrm{A}$, phase $\mathrm{B}$, and phase $\mathrm{C}$ currents at grid side of converter transformer, respectively. $u_{c a}, u_{c b}$, and $u_{c c}$ are the measured phase A, phase $\mathrm{B}$, and phase $\mathrm{C}$ voltages at valve side of converter transformer, respectively. $L$ is the equivalent reactance. $R$ is the equivalent resistance.

After the park transformation, the active power $P$ injected into the converter station from the AC system is as (5). The

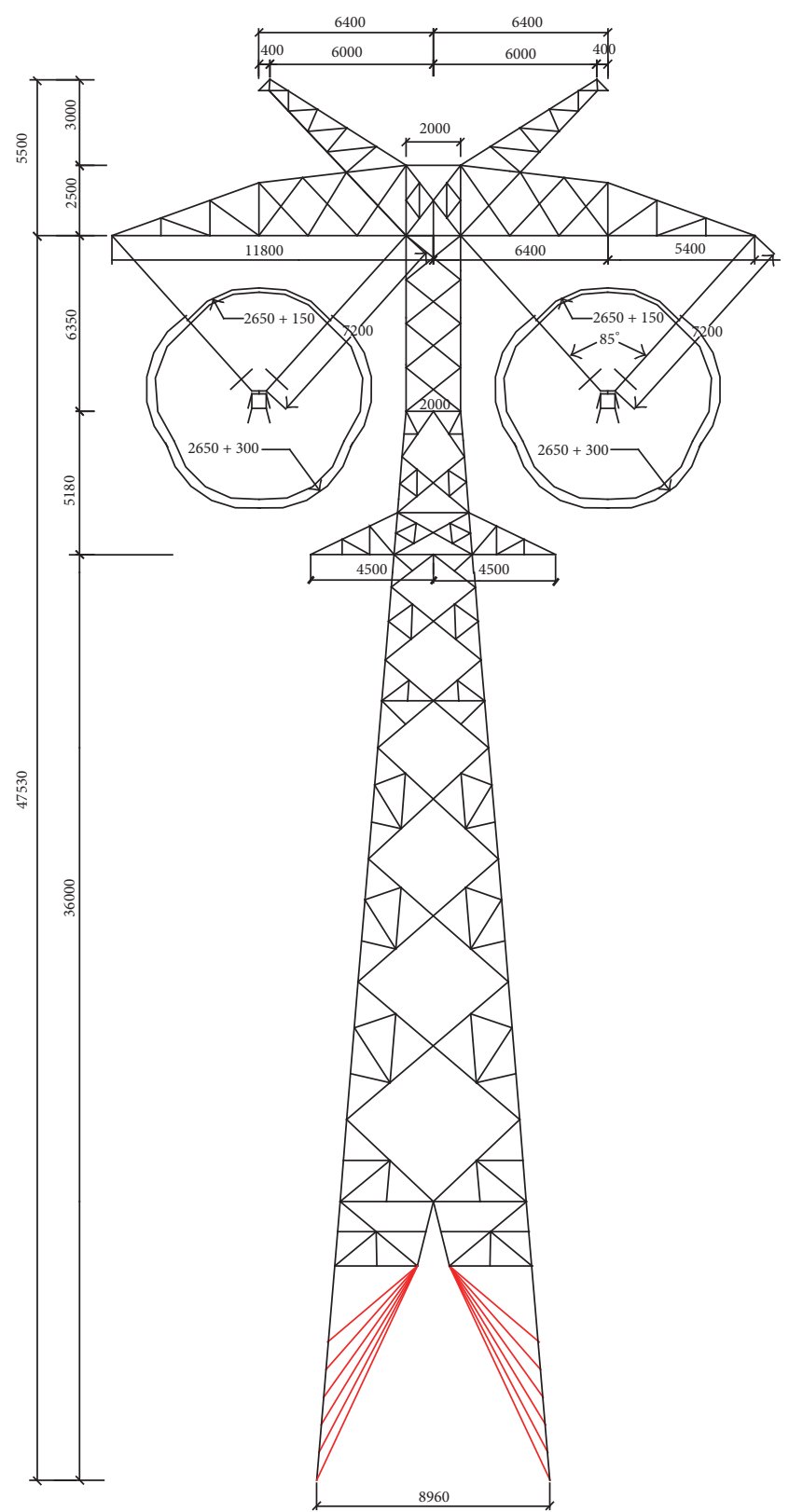

FIgURE 2: Typical tower diagram of single circuit transmission line.

reactive power $Q$ injected into the converter station from the AC system is as (6). So the decoupled control of active power and reactive power can be realized:

$$
\begin{aligned}
& P=\frac{3}{2}\left(u_{s d} i_{s d}+u_{s q} i_{s q}\right)=\frac{3}{2} u_{s d} i_{s d}, \\
& Q=\frac{3}{2}\left(u_{s d} i_{s q}-u_{s q} i_{s d}\right)=\frac{3}{2} u_{s d} i_{s q},
\end{aligned}
$$

where $u_{s d}$ and $u_{s q}$ are the $d$ axis and $q$ axis voltages derived from park transformation of $u_{s a}, u_{s b}$, and $u_{s c}$, respectively. $i_{s d}$ and $i_{s q}$ are the $d$ axis and $q$ axis currents derived from park transformation of $i_{s a}, i_{s b}$, and $i_{s c}$, respectively. 


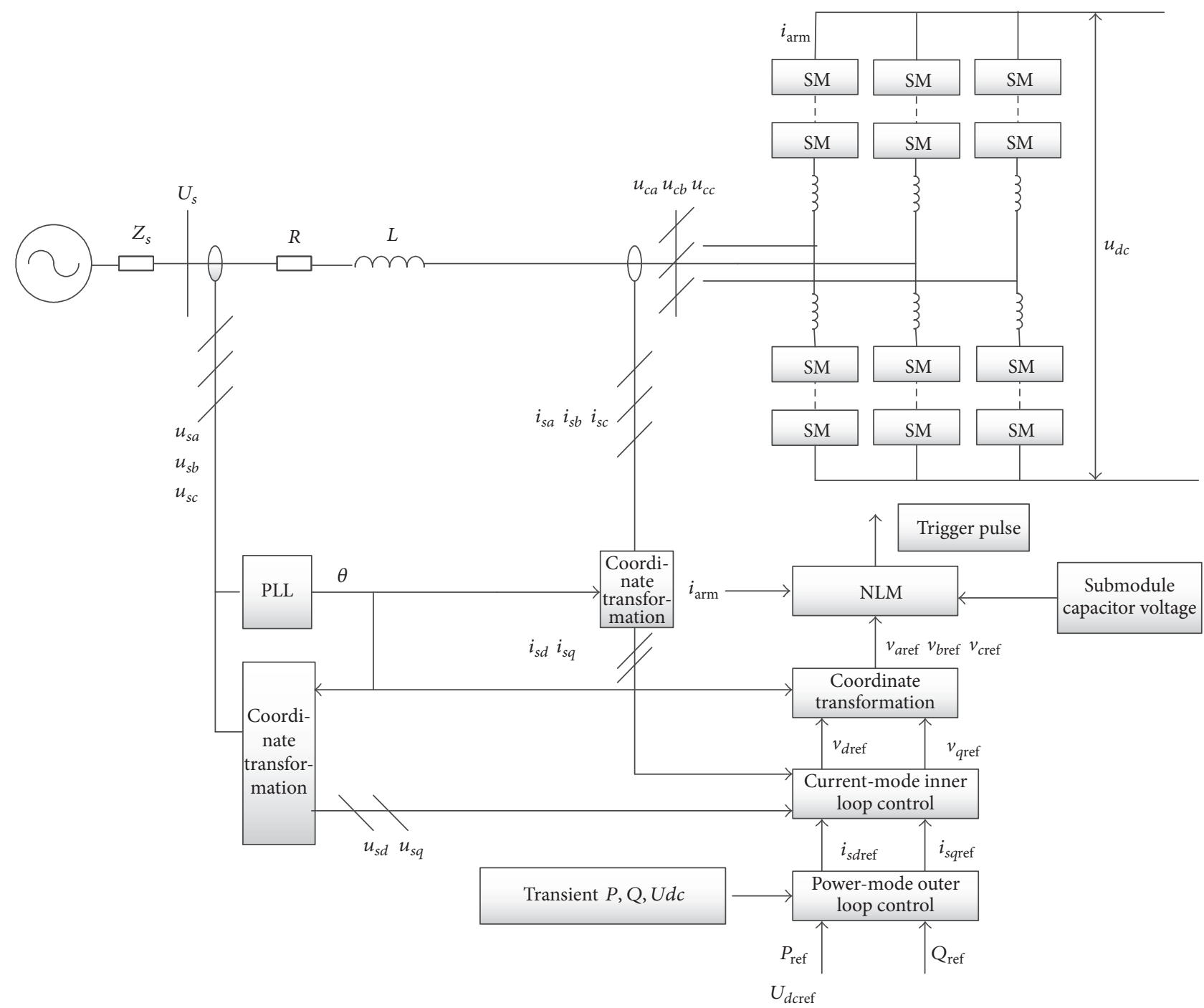

FIgURE 3: The schematic diagram of MMC control system.

3.1.3. Wind Power Model. Two wind farms provide the power sources for 2 substations of the 4 -terminal $\pm 500 \mathrm{kV}$ MMCHVDC project. In order to calculate the accurate overvoltage level, the influence of the wind farms on overvoltage was considered.

In the simulation, the electromagnetic transient model based on the $d q 0$ transform of doubly fed induction generator was established. The $d q$ coordinate system based on rotation speed of rotor was adopted. The voltage and current on the armature side and the exciting side satisfy [17]

$$
\begin{aligned}
& V_{P}=-R_{P} i_{P}-\frac{d \lambda_{P}}{d t}+\omega N \lambda_{P} \\
& V_{E}=-R_{E} i_{E}-\frac{d \lambda_{E}}{d t} \\
& N=\left[\begin{array}{ccc}
0 & 0 & 0 \\
0 & 0 & -1 \\
0 & 1 & 0
\end{array}\right]
\end{aligned}
$$

where $V_{P}$ and $V_{E}$ are voltages on the armature side and the exciting side, respectively. $R_{P}$ and $R_{E}$ are resistance on the armature side and resistance on the exciting side, respectively. $i_{P}$ and $i_{E}$ are currents on the armature side and the exciting side, respectively. $\lambda_{P}$ and $\lambda_{E}$ are flux linkage matrixes on the armature side and the exciting side, respectively. $\omega$ is the angular velocity of rotor rotation.

3.2. Overvoltage Analysis. Two modes of operation are considered during the simulation:

(1) Normal mode:

All the stations access the network.

(2) Abnormal mode:

Some of the stations are unconnected to the network, which leads to a longer transmission line than normal mode.

The specific calculation process is as follows. The DC operation voltage is $535 \mathrm{kV}$ before fault. The fault line is 
TABLE 1: Overvoltages of transmission lines under normal mode.

\begin{tabular}{lcc}
\hline \multirow{2}{*}{ Lines } & \multicolumn{2}{c}{ Overvoltages of pole lines } \\
& $\mathrm{kV}$ & p.u. \\
\hline A-D & 950 & 1.78 \\
C-D & 974 & 1.82 \\
B-C & 991 & 1.85 \\
A-B & 888 & 1.66 \\
\hline
\end{tabular}

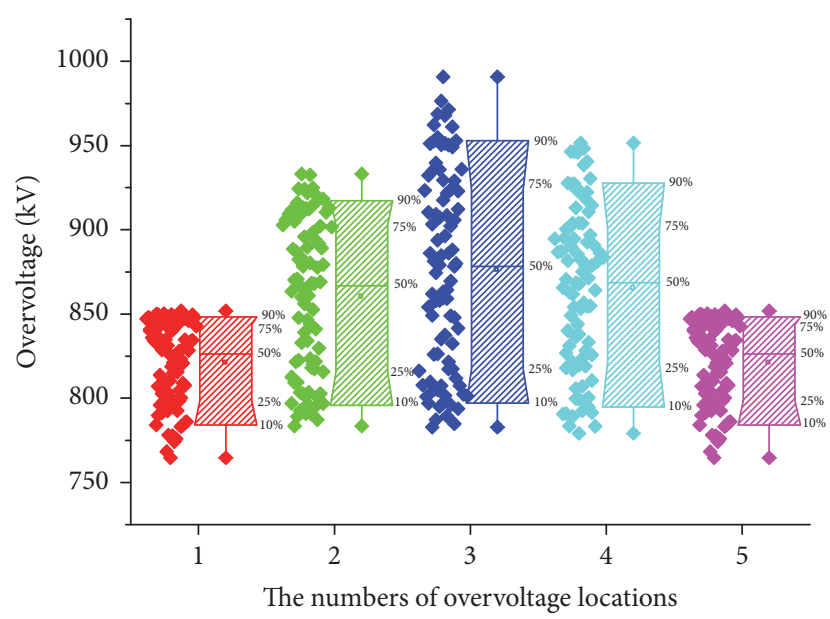

FIGURE 4: The overvoltage distribution and probability distribution of B-C line caused by A-D line fault under normal mode.

divided into 10 sections. Along the line each section is grounded. Then the circuit breakers at the ends of fault line trip remove the temporary ground fault, and after the delay time the DC circuit breakers reclose. Both the overvoltages caused during the grounding and reclose processes are taken into consideration. Besides, the overvoltages caused by faults on other lines should be calculated too.

3.2.1. Normal Mode. The overvoltage levels of all pole lines are shown in Table 1 . The maximum overvoltage of $990.77 \mathrm{kV}$ $(1.85$ p.u., 1 p.u. $=535 \mathrm{kV})$ appeared in the $\mathrm{B}-\mathrm{C}$ line, caused by the A-D line fault. The overvoltage distribution and probability distribution of B-C line are shown in Figure 4. The statistics overvoltage along the line is umbrella type distribution. In the middle of line the overvoltage is high and to both ends of the line diminishing. This is due to the installation of the arrester on the pole line bus, which can suppress the overvoltage.

3.2.2. Abnormal Mode. The overvoltage levels of all pole lines were simulated under abnormal mode, which means some of the stations were unconnected to the DC grid during the simulations. The maximum overvoltage, out of hundreds of simulation results of different unconnected stations, occurred in case $\mathrm{C}$ station is unconnected. In this section, overvoltages of transmission lines when $\mathrm{C}$ station is unconnected are shown in Table 2. The maximum overvoltage has the peak of $1034 \mathrm{kV}(1.93 \mathrm{pu})$, appearing in the CD line, caused by
TABLE 2: Overvoltages of transmission lines under abnormal mode (C station is unconnected).

\begin{tabular}{lcc}
\hline \multirow{2}{*}{ Lines } & \multicolumn{2}{c}{ Overvoltages of pole lines } \\
& $\mathrm{kV}$ & p.u. \\
\hline A-D & 998 & 1.87 \\
C-D & 1034 & 1.93 \\
B-C & 1010 & 1.89 \\
A-B & 896 & 1.68 \\
\hline
\end{tabular}

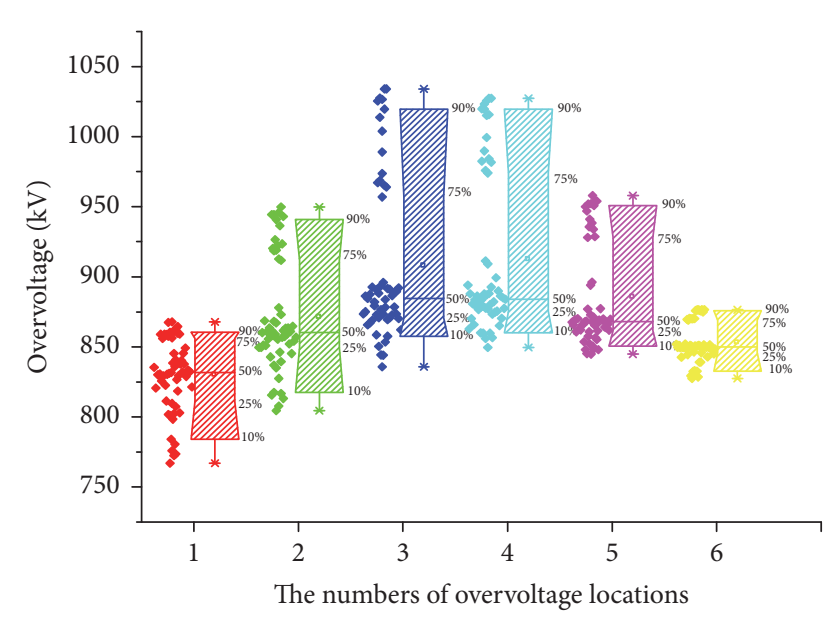

FIgURE 5: The overvoltage distribution and probability distribution of C-D line caused by A-B line fault with unconnected C station.

the A-B positive line ground fault. The overvoltage distribution and probability distribution of C-D line are shown in Figure 5, under situation of the unconnected $\mathrm{C}$ station. The maximum overvoltage waveform and the corresponding pole bus waveform are shown in Figure 6. It can be seen that the maximum overvoltage occurs during the DC circuit breaker opening process. Depending on the time difference between peaks, the peaks of the waveform in Figure 6 were caused by the different wave velocities of reflected positive sequence and zero sequence waves.

\section{Insulation Coordination of Pole Lines}

According to IEC 60071-3, the switching impulse 50\% flashover voltage $U_{50 \% \text { s }}$ of air gap between wire and tower can be calculated in (10), which can be used for insulation coordination of pole lines:

$$
U_{50 \% s}=\frac{K_{a} K_{3}^{\prime}}{\left(1-2 \sigma_{s}\right)} U_{m}
$$

where $U_{m}$ is maximum voltage of system $(535 \mathrm{kV}$ in this paper), $K_{a}$ is discharge voltage correction coefficient of air density and humidity of the switch impulse voltage, $K_{3}^{\prime}$ is the per unit value of overvoltage, and $\sigma_{s}$ is the standard deviation.

Altitude correction can be conducted by IEC 60071-2 with safety margin. The calculation formula is showed by

$$
K_{a}=e^{m(H / 8150)},
$$


TABLE 3: Required values of air gaps under switch impulse overvoltage for a 4-terminal MMC-HVDC project.

\begin{tabular}{|c|c|c|c|c|c|}
\hline \multirow{2}{*}{ Lines } & \multirow{2}{*}{ Switching overvoltage level (p.u.) } & \multirow{2}{*}{ Required $50 \%$ switching impulse discharge voltage } & \multicolumn{3}{|c|}{ Altitude (m) } \\
\hline & & & 0 & 1000 & 2000 \\
\hline A-D & 1.9 p.u. & 1130 & 2.73 & 3.13 & 3.63 \\
\hline C-D & 1.93 p.u. & 1147 & 2.79 & 3.21 & 3.73 \\
\hline $\mathrm{B}-\mathrm{C}$ & 1.9 p.u. & 1130 & 2.73 & 3.13 & 3.63 \\
\hline A-B & 1.7 p.u. & 1011 & 2.4 & 2.75 & 3.2 \\
\hline
\end{tabular}
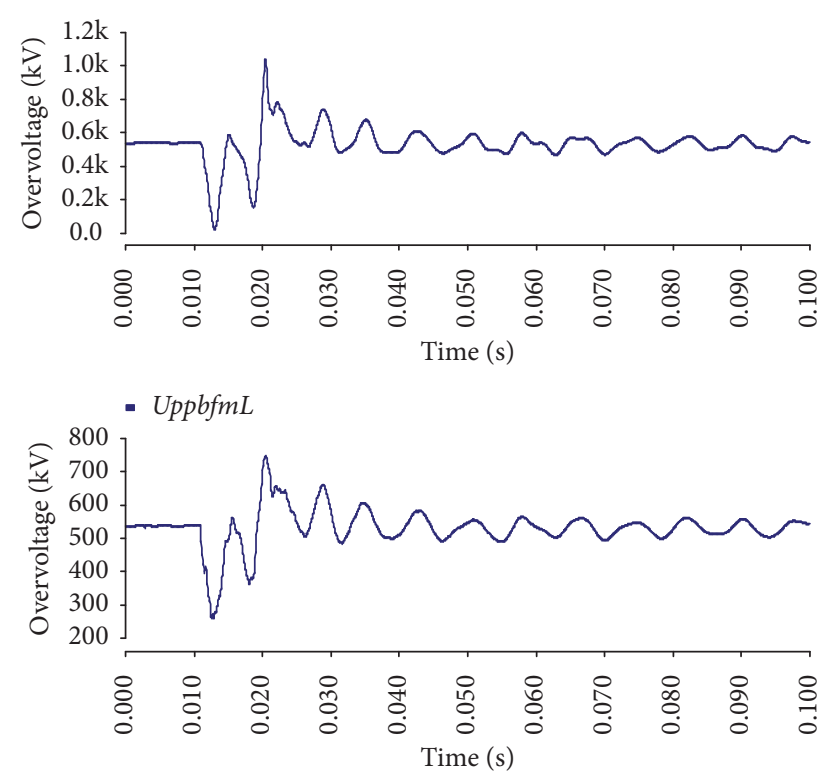

- BJ_PU

FIGURE 6: The waveforms of maximum overvoltage on C-D line and pole bus of $\mathrm{D}$ station under the mode of unconnected $\mathrm{C}$ station.

where $H$ is the altitude above sea level measured in meters and the value of $m$ depended on the type of voltage impulse.

The discharge curve of air gap of double circuit tower is provided by CEPRI tested on upper layer of $\pm 500 \mathrm{kV} \mathrm{DC}$ double circuit transmission line, and the discharge curve of air gap of single circuit tower is tested on $\pm 500 \mathrm{kV}$ real type tower with $\mathrm{V}$-type insulator string. The air gap flashover curve could be obtained by referring to relevant papers [18]. The calculated air gaps of single circuit and double circuit on one tower under switch impulse voltage are shown in Table 3 . The required values of air gaps are considered under normal mode and abnormal mode (without $\mathrm{C}$ substation).

\section{Conclusion}

(1) It is different from circuit breaker adopted MMCHVDC system and LCC-HVDC when confronted with overvoltage of transmission line. In LCCHVDC, only the induced overvoltage on sound line caused by single-pole line fault is considered. Besides the induced overvoltage, the fault clearing overvoltage and reclosing overvoltage of transmission line have to be taken into consideration in the case of multiterminal MMC-HVDC project.

(2) The statistics overvoltage on the sound line caused by ground fault presents the umbrella type distribution along the line. In the middle of line the overvoltage is high and to both ends of the line diminishing. In this paper, the simulated overvoltage of the project is up to 1.93 p.u., occurring during the DC circuit breaker clearing the DC side failure. The suppression measures of DC circuit breaker causing overvoltage need further study.

(3) The required minimal clearance of pole lines under switch impulse overvoltage can be selected as $2.79 \mathrm{~m}$ at an altitude of $0 \mathrm{~m}$. Differential air gap selection for various transmission lines is also recommended.

(4) The mechanism for the generation of overvoltages has not been clearly explained. The quantitative influence of the line length, the grounding mode of the valve side of converter, and the network structure on the overvoltage level should be further studied to support the project design.

\section{Conflicts of Interest}

The authors declare that there are no conflicts of interest regarding the publication of this paper.

\section{Acknowledgments}

The authors are grateful for the support provided by the National Key Research and Development Program of China (Grant 2016YFB0900900) and the SGCC Project of Overvoltage and Insulation Coordination Technology Research of $\pm 500 \mathrm{kV}$ Flexible DC Grid (GY71-15-076).

\section{References}

[1] H. Zhiyuan, Y. Zhao, and T. Guangfu, "Key Technology Research and Application of the $\pm 320 \mathrm{kV} / 1000$ MW VSC-HVDC," Smart Grid, vol. 4, pp. 124-132, 2016.

[2] M. Weimin, W. Fangjie, Y. Yiming et al., "Flexible HVDC Transmission Technology's Today and Tomorrow," High Voltage Engineering, vol. 40, pp. 2429-2439, 2014.

[3] T. Guangfu, H. Zhiyuan, and P. Hui, "Discussion on Applying the VSC-HVDC Technology in Global Energy Interconnection," Smart Grid, vol. 4, no. 2, pp. 116-123, 2016.

[4] H. Alyami and Y. Mohamed, "Review and development of MMC employed in VSC-HVDC systems," in Proceedings of the 
2017 IEEE 30th Canadian Conference on Electrical and Computer Engineering (CCECE), pp. 1-6, April 2017.

[5] L. Xingyuan, Z. Qi, W. Yuhong et al., "Control strategies of voltage source converter based direct current transmission system," Gaodianya Jishu/High Voltage Engineering, vol. 42, no. 10, pp. 3025-3037, 2016.

[6] N. Zhang, C. Kang, D. S. Kirschen et al., "Planning pumped storage capacity for wind power integration," IEEE Transactions on Sustainable Energy, vol. 4, no. 2, pp. 393-401, 2013.

[7] J. Lyu, X. Cai, and M. Molinas, "Frequency Domain Stability Analysis of MMC-Based HVdc for Wind Farm Integration," IEEE Journal of Emerging and Selected Topics in Power Electronics, vol. 4, no. 1, pp. 141-151, 2016.

[8] H. Chang, D. Chen, Y. Wu, and Y. Ma, "Analysis and optimization strategy of power disturbance on Xiamen flexible HVDC project," Gaodianya Jishu/High Voltage Engineering, vol. 42, no. 10, pp. 3045-3050, 2016.

[9] M. Weimin, J. Weiyong, and L. Yanan, "System design for dalian VSC-HVDC power transmission project," Electric Power Construction, vol. 34, no. 5, pp. 1-5, 2013.

[10] Z. Xu, G. Liu, and Z. Zhang, "Research on fault protection principle of DC grids," Gaodianya Jishu/High Voltage Engineering, vol. 43, no. 1, pp. 1-8, 2017.

[11] F. B. Ajaei and R. Iravani, "Cable surge arrester operation due to transient overvoltages under DC-side faults in the MMCHVDC link," IEEE Transactions on Power Delivery, vol. 31, no. 3, pp. 1213-1222, 2016.

[12] M. Wang, Y. Hu, W. Zhao, Y. Wang, and G. Chen, "Application of modular multilevel converter in medium voltage high power permanent magnet synchronous generator wind energy conversion systems," IET Renewable Power Generation, vol. 10, no. 6, pp. 824-833, 2016.

[13] Z. Chengyong, Modeling and Simulation of Flexible HVDC, China Electric Power Press, Beijing, China, 2014.

[14] F. Zhang, J. Xu, and C. Zhao, "New control strategy of decoupling the AC/DC voltage offset for modular multilevel converter," IET Generation, Transmission and Distribution, vol. 10, no. 6, pp. 1382-1392, 2016.

[15] Y. Dong, W. Ling, J. Tian et al., "Control protection system for Zhoushan multi-terminal VSC-HVDC," Electric Power Automation Equipment, vol. 36, no. 7, pp. 169-175, 2016.

[16] K. Ou, H. Rao, Z. Cai et al., "MMC-HVDC simulation and testing based on real-time digital simulator and physical control system," IEEE Journal of Emerging and Selected Topics in Power Electronics, vol. 2, no. 4, pp. 1109-1116, 2014.

[17] Z. Gu, Y. Tang, W. Liu et al., "Electromechanical transentelectromagnetic transient hybrid simulation of double-fed induction generator," Power System Technology, vol. 39, no. 3, pp. 615-620, 2015.

[18] W. Liao, Y. Ding, Z. Sun, and Z. Su, "Altitude correction of switching impulse flashover voltage of tower gaps with Vshaped insulator strings for HVDC power transmission lines," Dianwang Jishu/Power System Technology, vol. 36, no. 1, pp. 182188, 2012. 


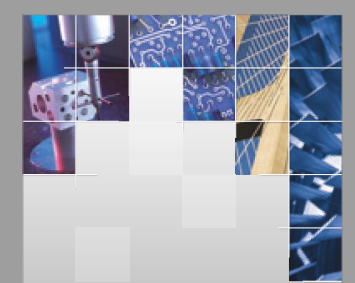

\section{Enfincering}
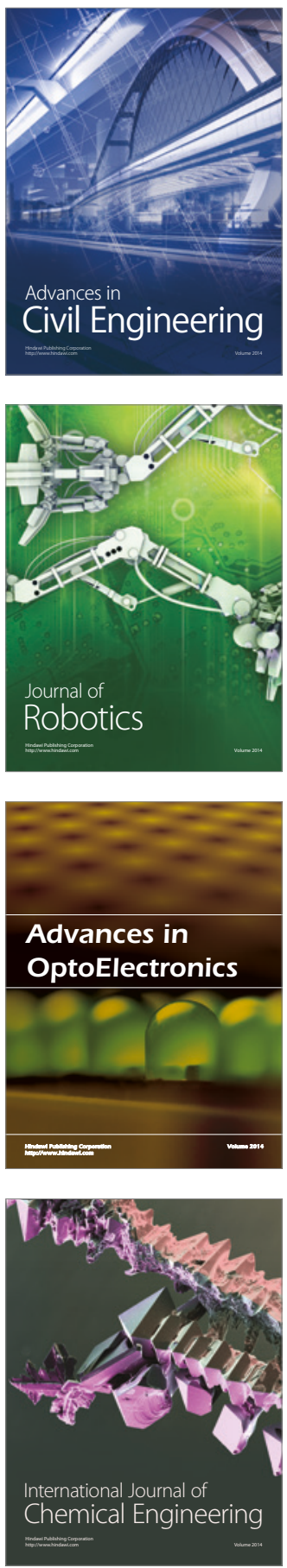

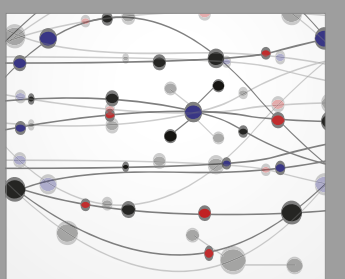

The Scientific World Journal

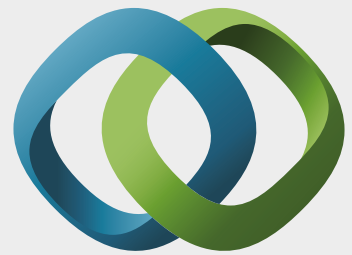

\section{Hindawi}

Submit your manuscripts at

https://www.hindawi.com
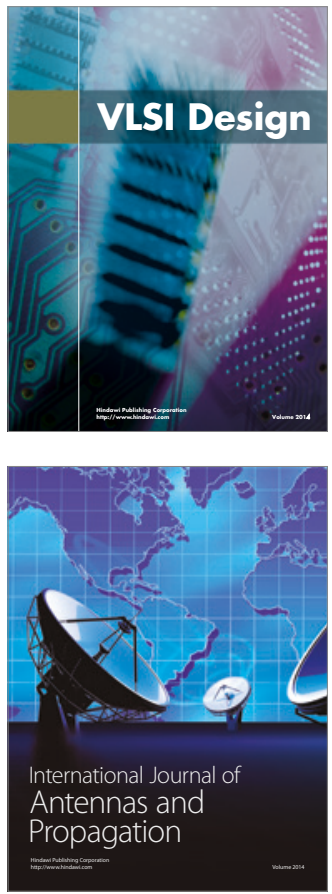

\section{Rotating}

Machinery
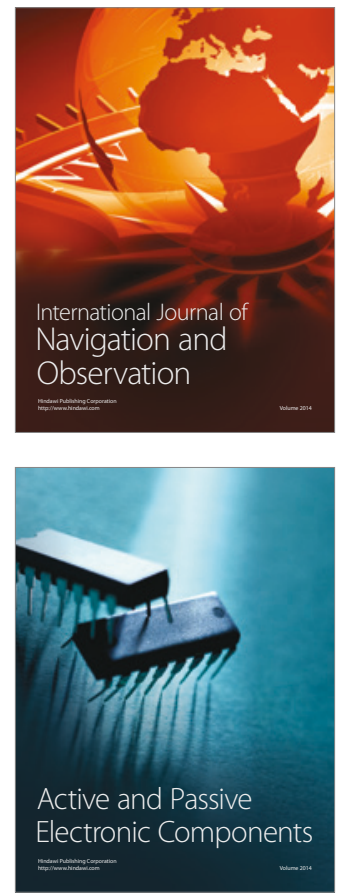
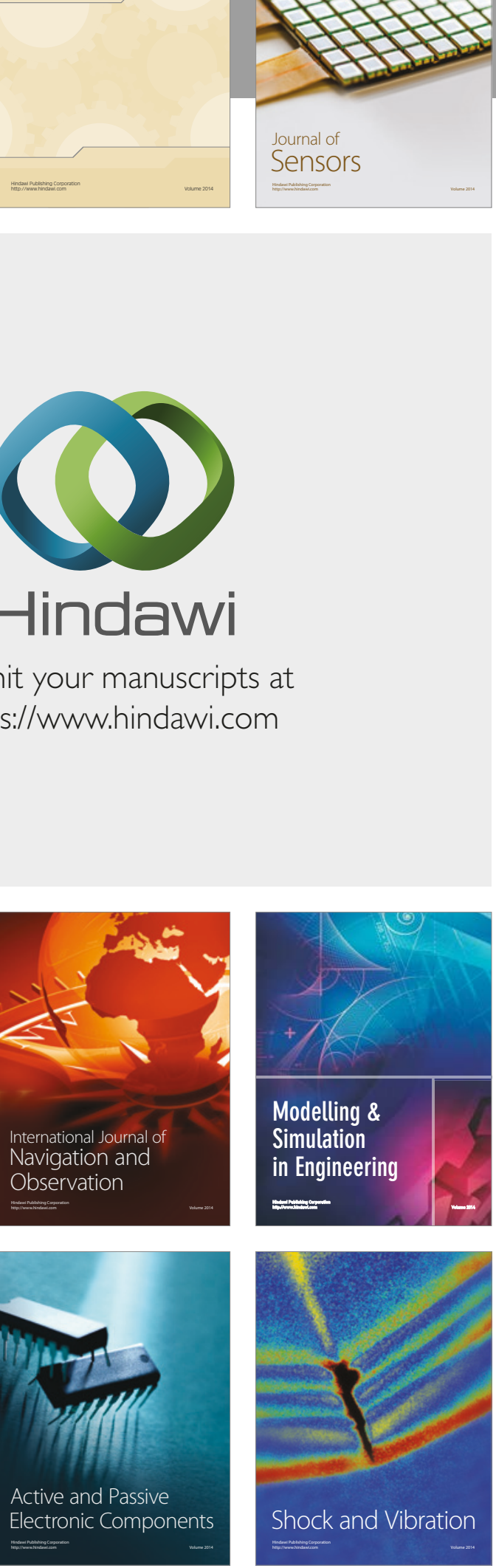
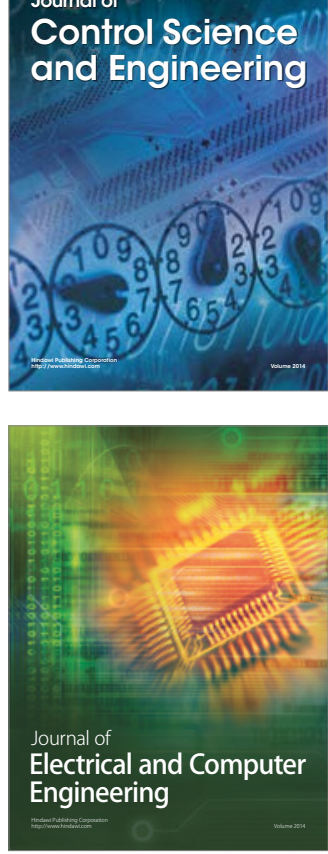

Distributed

Journal of

Control Science

and Engineering
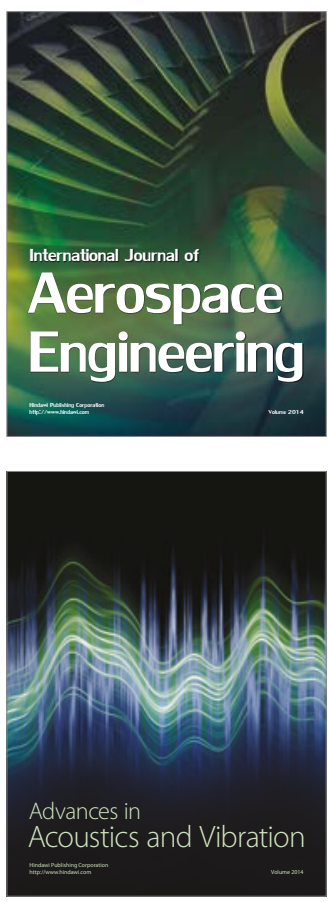

Sensor Networks 